Available online at www.jmle.org

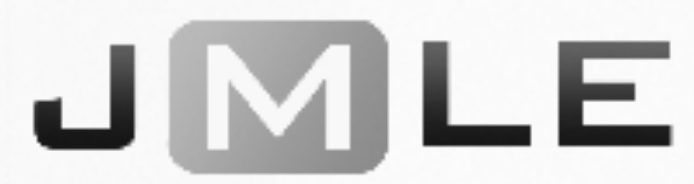

The National Association for Media Literacy Education's Journal of Media Literacy Education 10 (2), 33 - 52

\title{
Civic Media Literacy in a Transmedia World: Balancing Personal Experience, Factual Accuracy and Emotional Appeal as Media Consumers and Circulators
}

\author{
Ellen Middaugh \\ San Jose State University
}

\begin{abstract}
Amid growing concerns over the role of "fake news" in civic and political life, efforts to understand how to best prepare youth to evaluate and reason about online sources have gained a sense of urgency. However, less attention has been paid to how such skills are used in the context of the broader array of information behavior that is typical of civic and political participation today-particularly in the circulation of information. Through thematic analysis of interviews and think aloud tasks with $\mathrm{n}=24$ urban high school students reasoning through the processes of search, credibility analysis and circulating information for the purposes of issue advocacy, two considerations for civic media literacy education emerged. First, greater attention is needed to educating youth to coordinate the considerations for factual accuracy with the social and emotional components of civic media, particularly once they move beyond the task of being asked to assess media and into the tasks of searching for or choosing to share media. Second, greater attention is needed on circulation in civic media literacy and what it means to share information ethically and responsibly.
\end{abstract}

Keywords: civic education, adolescent, urban, transmedia circulation

We ask youth to be civically engaged for their own well-being but also to ensure a healthy democracy. They need to exercise rights to inform themselves about issues that impact them, and express their concerns in the public domain. They also have responsibilities to make informed decisions and understand how their expression impacts others. As we consider how to educate youth for informed, effective and ethical civic engagement in the era of "fake news," they must learn more than to detect and reject false information. They must also learn to integrate concerns for accuracy and evidence into everyday practices of consuming and sharing media.

Awareness of "fake news" increased following the 2016 Presidential election. However, concerns about whether people can use media to develop an accurate understanding of the world are not new and have been growing over the past two decades of technological change. As the internet and technology enable a wider array of people to produce and circulate content, 
transmedia practices - how one engages with information across a wide variety of media sources and platforms (Jenkins, Purushotma, Clinton, Weigel \& Robinson, 2006)-have become important. Rather than assessing a single in-depth article distributed by a known source, one may see information repeated in multiple locations, in different formats, with different pieces excerpted or highlighted and must make a series of quick judgments about how to fit these pieces into their understanding of an issue. Within this context, whether they encounter hoaxes, conspiracy theories or fabrication associated with fake news (Mihailidis \& Viotty, 2017), parody or satire (Tandoc, Lim \& Ling, 2018), or outrageous language as an accompaniment or substitute for evidence-based arguments (Berry \& Sobieraj, 2014), we hope that youth will be motivated and able to assess the media they encounter for evidence and factual accuracy.

Currently, there are concerns that this is not the case. A 2017 Common Sense Media survey found only $44 \%$ of teens agreed they could tell the difference between real and fake news, and $31 \%$ of those who had shared news in the last 6 months shared something false. In light of this, recent studies have demonstrated promising strategies for teaching and assessing youth abilities to evaluate the accuracy of information (Kahne \& Bowyer, 2017; Martens \& Hobbs, 2015; McGrew, Breakstone, Ortega, Smith, \& Wineburg, 2018). This assumes that if youth learn to detect false information, they will make better decisions in their day-to-day practices of consuming, circulating, commenting on and/or producing media as part of their engagement with public life. However, the everyday practices of media use for civic information and expression depart from this assumption in three important ways.

First, detecting and discarding false information is only one part. Often, people have to decide how to integrate imperfect information-firsthand experience, opinion, or incomplete facts - into their understanding of an issue. Second, how we interact with media is rarely a linear process of searching for information, selecting the best source and then sharing. Rather, we move between tasks at varied rates, sometimes going down a rabbit hole of search to validate information shared in a story on an issue but then later sharing similar information we encounter, perhaps with less scrutiny. Finally, when we engage with media for civic purposes, we may care that it represents objective facts, but there are social and emotional considerations such as whether the story or media post represents our experiences, is emotionally resonant, or feels morally compelling.

If we conceptualize civic media literacy, as Mihailidis (2018) does, as more than mastery of a set of process skills but the ability to use these skills with "civic intentionality" in the context of everyday participation, then our concerns for whether and how youth assess the accuracy of media should be studied within the context of everyday practices and civic intentions. Toward that end, I use a small but rich qualitative data set drawn from think-aloud interviews conducted in 2014 with $n=24$ urban high school students in which they engaged in an Issue Advocacy Task that asked them to think through how to search for information, evaluate media presented to them, and make choices about what kind of media to circulate for the purposes of raising awareness about a social issue. The question guiding this study was, "What are the barriers to youth consideration of factual accuracy when engaging in the practices of search, evaluation and circulation of media for the purposes of issue advocacy?"

\section{THEORETICAL FRAMEWORK}

In line with recent work that reimagines Barber's (1984) framework of participatory politics for the digital age, I define civic engagement as including a range of practices through 
which individuals and groups seek to influence public agenda-setting and action (Cohen \& Kahne, 2012; Kahne, Hodgin \& Eidman-Aahdal, 2016). Particularly noteworthy from this perspective is the argument that relatively small acts of investigation (seeking out information), dialogue and feedback (commenting on media), circulation, and production of media become meaningful acts of civic participation when done in an online, networked setting that combines small acts over time and across people.

In order to gain a better understanding of what it would mean to teach youth to engage in these practices effectively for the purposes of informed, effective and ethical civic engagement, I drew on Hobbs' (2010) essential competencies of digital and media literacies, which include the ability to access information, analyze and evaluate messages, create content for an audience, reflect on responsible media use, and act to share knowledge and solve problems. In merging this framework with the participatory politics framework, I focused the think aloud interviews on the acts of search ("access"/"investigate"), evaluation ("analyze \& evaluate"/"investigate") and circulation of media for the purposes of issue advocacy.

Additionally, I adopt Mihailidis' (2018) definition of civic media literacy as the ability to use media with civic intentionality and attention to democratic principles. Thus, the analysis of participants' practices of search, evaluation, and circulation for issue advocacy focused on how well their approach to these practices supported the democratic principle of free flow of information and equality of interaction articulated by Dewey $(1916 ; 1927)$ as critical to a thriving democracy. Specifically, I focused on the extent to which they attended to the factual accuracy of information (as it is hard to imagine equality of interaction based on misleading media) as they participated in the flow of information by searching, evaluating, and circulating media.

\section{LITERATURE REVIEW}

\section{Youth Evaluation of Civic Media}

Recent research on youth abilities to evaluate media about social or political issues (referred to henceforth as civic media to contrast it with media consumed purely for entertainment) has focused on their ability to assess the credibility of media in the context of an explicit evaluation task. This research suggests that overall, youth struggle with this. For example, McGrew et al. (2018) studied civic online reasoning, defined as the "ability to effectively search for, evaluate, and verify social and political information online," (p. 165) by providing participants with examples of civic media in a variety of formats (web page, tweet, etc.) and asking them to analyze the source for evidence or usefulness. They found that participants struggled to effectively evaluate information, with only a small percentage of both high school and college participants demonstrating "mastery level" in their explanations.

Kahne and Bowyer (2017) showed a national sample of youth "posts" with either an emotive, evidence-based or misinformative argument about income inequality and asked participants to evaluate whether the argument was accurate. They found that more than half of participants in the misinformation condition and three quarters in the emotive condition rated these arguments as accurate when the position aligned with their own ideology. More encouragingly, Kahne and Bowyer (2017) found that those who had prior experience with media literacy education were significantly less likely to endorse misinformation. However, there is quite a bit that we do not understand about whether and how youth apply strategies to assess the accuracy of information in contexts that are more typical of every day civic media use. 


\section{Areas in Need of Further Exploration}

Media consumption and circulation as everyday practices of participatory politics. In civic education (Blevins, LeCompte \& Wells, 2016), media literacy education (Hobbs, Donnelly, Friesem \& Moen, 2013), and youth journalism (Clark \& Marchi, 2017) a common model is to engage students in a process of first researching information about an issue and then using that information for publication or action, followed by reflection. This process has much to recommend by preparing youth to work collectively to make their voices heard. It is with good reason that this type of process is frequently cited as best practice in civic education.

As scholars and leaders in the field of civic education have begun trying to respond to the need to prepare youth for the practices of participatory politics (particularly with digital media), they have made suggestions for educators to integrate practices of digital search, analysis of credibility, circulation and production of media, online dialogue and/or mobilization into the classroom (Kahne et al., 2016) often as part of a broader inquiry and action project (Middaugh \& Evans, 2018). However, our day-to-day civic media practices are far less organized and orderly. Circulation is often not the culminating act after engaging in inquiry but a daily practice of sharing what we notice. Sometimes we engage in active searches for information, but frequently information arrives in our feeds from varying sources with varying amounts of context (Clark \& Marchi, 2017).

While it is important and worthwhile to teach for organized and thoughtful inquiry and action, it is also useful to consider how we can improve our smaller, less organized but more frequent acts of civic inquiry and expression. Towards this end, the Issue Advocacy Task that youth were given asked them to reason through the practices of search, evaluation and circulation as separate tasks organized around the same topic rather than as steps in a process that relied on the successful completion of the prior task.

Transmedia judgment. Just as our personal acts of civic media use are not organized in a linear fashion, neither is the media we consume. Jenkins and colleagues (Jenkins et al, 2006) have argued that "transmedia navigation" and "transmedia judgment," which refer to the ability to sort through and make sense of information gathered across multiple media formats and authors and to make judgments about these dynamics when exercising voice, are critical media literacy skills. Bringing these concepts to the civic and political realm, Lan (2013) has argued that democratic education now requires attention to transmedia judgement. In light of recent findings that $76 \%$ of youth get news through social media, including Facebook, Snapchat, Reddit, Instagram and YouTube (Common Sense Media, 2017), the argument for transmedia judgment is quickly validated. These sources vary considerably in format and may include links to news articles reported by trained reporters, user generated video, infographics, edited snippets of text (common on Twitter), pictures with only a hashtag, etc. Youth today are tasked with coordinating all of these elements as they seek to construct their understandings of social and political issues as well as when they think about how to best enter into public discourse and amplify their own voices.

While transmedia judgment has been well conceptualized, it has not been extensively studied empirically, particularly within the context of youth civic engagement. The current study was not designed to assess transmedia judgment per se, but the use of multiple media formats (blogs, videos, infographics, online news, websites) and the close analysis of participants' efforts to assess the credibility of different media and formats provided some insight into the challenges of transmedia judgment and the need to teach towards this broader process.

The role of social and emotional elements in defining "high quality" information. As we see more attention to the problem of fake news, research has typically examined the social and 
emotional elements of civic media as impediments to the accurate assessment of information. Research on motivated reasoning (Kahne \& Bowyer, 2017), and incivility and outrage language (Graf, Erba \& Harn, 2017) suggests that our social attitudes, emotional responses and ideology can act as barriers to developing an accurate assessment of media. One potential educational response to this is to train youth to gravitate toward neutral or objective sources that are backed by reputable people or organizations.

However, as both Grabe and Myrick (2016), and Clark and Marchi (2017) have noted, much of what inspires civic action lies in the personal, social and emotional. Therefore, simply pushing youth towards neutral or elite sources may backfire. For example, Clark and Marchi's (2017) study of youth journalists found that they frequently favored content that was user generated and included features that are often seen as counter to standards of objectivity such as strong emotional language, moral evaluations, or calls to action. While Clark and Marchi's (2017) participants had learned and understood the importance of evidence, they also saw reporting of the emotional or moral stakes of an issue as important to their understanding. Grabe and Myrick (2016) have argued that stripping news of the elements of emotion, moral stakes or first-person narrative for the sake of objectivity runs the risk of alienating and demotivating people who feel such representations are not reflective of their experience.

In a similar vein, the emotional and personal stakes represented in media were factors that emerged in the current study participants' judgments about how to best search for and circulate civic media.

\section{RESEARCH METHODS}

The current study used data collected between May - October 2014 as part of a larger study of a district-wide professional development initiative to integrate digital and civic education supports into high school humanities courses. In order to gain insight into meaningful variations in youths' everyday civic media literacy practices, the research team designed a think aloud Issue Advocacy Task in which participants were asked to talk through how they would make decisions about finding, evaluating and circulating media to raise awareness about a civic issue. This data collection was conducted with a small subset of students within the classrooms and schools where teachers were beginning to change their classroom practices.

\section{Participants}

A total of 24 male and female $9^{\text {th }}-11^{\text {th }}$ grade students participated in the interview. Half of the participants $(n=12)$ were recruited from 3 classrooms in which teachers had integrated digital media into civic inquiry and action projects in the classroom. Each teacher was situated in a different high school. The other half $(n=12)$ were recruited from 4 classrooms where no such special efforts were yet taking place (either in a class with the same teacher at the beginning of the following school year or in a different class in the same school setting). The demographic profiles of the school contexts from which students were selected are presented in Table 1.

\section{Issue Advocacy Task}

The Issue Advocacy Task was designed to examine the criteria participants used to make decisions about media use in the context of raising awareness about civic issues both within and across three common practices of searching for, evaluating and circulating media. Materials were organized around four topics that were observed as common topics selected by youth in their 
culminating senior research projects within the district-teen pregnancy, school safety, LGBTQ rights and teen employment. Participants were asked to choose one of the topics and then were led through a series of activities, including:

Search. Participants were given the starting prompt, "Some people think [issue they chose] is a big problem, some say it's not such a big problem. Those who say it's not a problem think [issue they chose] doesn't really affect that many people. I want to look up some information online that will tell me how many young people in [local city] will be affected by this." Following the prompt they were asked to direct the researcher in a search for relevant information to answer the question through providing the browser, search terms and reasoning for choosing articles.

Credibility Evaluation. Participants were then asked to examine an article selected by researchers ahead of time. Articles were drawn either from a reputable non-profit research and policy advocacy organization or a local newspaper. Students were given the prompt, "I'm going to want to use this information to convince other people that we really need to do something about this. In that case, it's really important that I think the information is right. What would you suggest I look for to decide if I can trust what this article says?" These articles were available online so that participants could search within the article and the website, though they were not prompted to do so.

Circulation. Finally, participants were asked about the best methods for sharing information to raise awareness and influence others to care about the issue. First, the interviewer showed the participant three different forms of media - an infographic, a blog post, and a video. The infographics and videos were typically user-generated content or content that was presented outside of the context in which it was created (for example through YouTube or Google Images). Blog posts were presented within the context of the blogs in which they originated. The goal was to present the level of information that would typically be available if this information was shared via social media. Participants were asked to assess which format was best for raising awareness and persuading others to pay attention.

Following the Issue Advocacy Task, participants were also asked to describe their previous experiences with supports for searching for, assessing the credibility of, and producing and circulating information as well as for learning about, analyzing and acting on civic issues. Interviews were audio recorded and transcribed, and screenshots were taken during the online search portion of the interview to capture the search terms and narrowing of information.

\section{Approach to Data Analysis}

Interviews were coded using thematic analysis (Braun \& Clarke, 2006). This approach was deemed most appropriate since the interviews were designed to examine specific theoretically derived categories of practice (Search, Evaluation, Circulation). The data were first coded deductively to compare strategies used by students of teachers who were and were not part of the Initiative. The author and one other member of the research team first coded data by broad category of practice, meeting to resolve any differences. Each coder then reviewed one transcript separately, generating a list of strategies participants used within each practice, looking for strategies such as using elements of the CRAAP Test (Currency, Relevance, Authority, Accuracy, and Purpose), analysis of perspectives being represented, and persistence in search. Coders met to compare and reach consensus. This process was repeated with additional transcripts until no new codes emerged. At that point the team re-coded any previously coded transcripts. Given the small sample size, inter-rater reliability was not calculated. Coders discussed and resolved any remaining 
E. Middaugh | Journal of Media Literacy Education 2018 10(2), 33 - 52

Table 1

Demographic Makeup of School Contexts During the Period of Data Collection

\begin{tabular}{|c|c|c|c|c|c|c|c|c|c|c|}
\hline & \multicolumn{2}{|c|}{ School 1} & \multicolumn{2}{|c|}{ School 2} & \multicolumn{2}{|c|}{ School 3} & \multicolumn{2}{|c|}{ School 4} & \multicolumn{2}{|c|}{ School 5} \\
\hline & $\begin{array}{l}2013- \\
14\end{array}$ & $\begin{array}{l}2014- \\
15\end{array}$ & $\begin{array}{l}2013- \\
14\end{array}$ & $\begin{array}{l}2014- \\
15\end{array}$ & $\begin{array}{l}2013- \\
14\end{array}$ & $\begin{array}{l}2014- \\
15\end{array}$ & $\begin{array}{l}2013- \\
14\end{array}$ & $\begin{array}{l}2014- \\
15\end{array}$ & $\begin{array}{l}2013- \\
14\end{array}$ & $\begin{array}{l}2014- \\
15\end{array}$ \\
\hline Free/Reduced Lunch & $53.6 \%$ & $55.8 \%$ & $77.9 \%$ & $75.6 \%$ & $82.8 \%$ & $75.8 \%$ & $88.5 \%$ & $80.7 \%$ & $94.3 \%$ & $85.0 \%$ \\
\hline Cohort Graduates & $86.1 \%$ & $88.7 \%$ & $69.7 \%$ & $74.4 \%$ & $48.2 \%$ & $54.3 \%$ & $77.2 \%$ & $69.7 \%$ & $76.5 \%$ & $85.3 \%$ \\
\hline $\begin{array}{l}\text { Black or African } \\
\text { American }\end{array}$ & $36.2 \%$ & $33.7 \%$ & $34.7 \%$ & $33.2 \%$ & $28.9 \%$ & $25.9 \%$ & $40.3 \%$ & $38.8 \%$ & $8.8 \%$ & $7.9 \%$ \\
\hline Hispanic or Latino & $18.7 \%$ & $19.4 \%$ & $37.2 \%$ & $39.5 \%$ & $54.5 \%$ & $59.6 \%$ & $51.2 \%$ & $53.5 \%$ & $79.7 \%$ & $82.7 \%$ \\
\hline Asian or Pacific Islander & $18 \%$ & $18.9 \%$ & $17.8 \%$ & $17 \%$ & $12.4 \%$ & $10.9 \%$ & $5.9 \%$ & $5.5 \%$ & $7.9 \%$ & $7 \%$ \\
\hline White & $22 \%$ & $22.5 \%$ & $6.5 \%$ & $6.6 \%$ & $1.6 \%$ & $1.9 \%$ & $0.5 \%$ & $0.2 \%$ & $1.9 \%$ & $.8 \%$ \\
\hline Other & $5.1 \%$ & $5.5 \%$ & $3.8 \%$ & $3.7 \%$ & $2.6 \%$ & $1.7 \%$ & $2.1 \%$ & $2 \%$ & $1.7 \%$ & $1.6 \%$ \\
\hline $\begin{array}{l}\text { Ethnic Diversity Index (0- } \\
100)\end{array}$ & 62 & 63 & 56 & 55 & 45 & 41 & 41 & 40 & 22 & 19 \\
\hline Total Enrollment & 2092 & 2014 & 1781 & 1845 & 727 & 811 & 564 & 505 & 419 & 481 \\
\hline
\end{tabular}


differences in codes applied. A comparison of strategies used between the two groups of students did not yield any notable differences. After returning to the interviews with the non-Initiative students, it was clear from their report of previous experiences that they had had prior opportunities to learn similar strategies, thus not representing a group of students with collectively different educational experiences.

From there, the data analysis focused on the priority of generating insights into challenges youth face when applying media literacy strategies in the context of issue advocacy. At this point the dataset was analyzed inductively moving back and forth between themes in the literature and themes observed in the data. The two researchers separately generated memos by practice, noting emerging themes in how participants approached the task to consider in addition to use of strategies that guided the first round of coding. These included references to personal experience/personal relevance, social or emotional elements of the message as persuasive, the presence of naïve or misleading credibility indicator (e.g., use of .org as credible), and explicit attempts to balance factual and non-factual elements in their judgments of credibility. Transcripts were then re-coded by both researchers using these new criteria. Following coding, the researchers met to resolve any discrepancies. From there, the author created a visual chart to summarize the data, as shown in Table 2, organized into a case (student) by practice (search, evaluation, circulation) matrix with codes that were present entered into each cell. This allowed for analysis of patterns within and across practices. From there, the author used individual excerpts to drill down and provide additional description and analysis.

Specifically, data were analyzed for: (a) whether and how factual accuracy factored into participants' judgments when finding, evaluating and circulating information for the purposes of issue advocacy; (b) challenges that emerged when participants attempted to apply strategies for assessing the credibility of information when analyzing online media about civic issues, and; (c) whether and how participants coordinated considerations for factual accuracy, personal relevance and emotional appeal when finding, evaluating and circulating information.

\section{FINDINGS}

These data were analyzed to highlight and add empirical examples of aspects of civic media literacy raised in prior theoretical work and to raise new considerations for how we conceptualize and study civic media literacy. I present the data in three sections. In section one, the patterns that emerged within and across practices are discussed, with exemplar quotes drawn from transcripts to illustrate. In sections two and three, I focus on surfacing examples of barriers to application of credibility criteria and different approaches to coordinating factual and non-factual considerations. Since sections two and three include analysis of sub-components of an already small data set, these observations are not presented in terms of prevalence of responses but types of responses that emerged that are theoretically interesting and potentially useful analytic categories to include in studies with larger samples. 
Table 2

Summary of Coded Data by Participant, Task and Strategy

\begin{tabular}{|c|c|c|c|}
\hline Participant & \multicolumn{3}{|c|}{ Component of Issue Advocacy Task } \\
\hline & Search & Evaluation & Circulation \\
\hline S1 & $\mathrm{C} ; \mathrm{PE}$ & $\mathrm{N} ; \mathrm{PE}$ & PE \\
\hline $\mathrm{S} 2$ & $\mathrm{~N}$ & $\mathrm{~N}$ & $\mathrm{SE}$ \\
\hline S3 & $\mathrm{C}$ & $\mathrm{C}$ & $\mathrm{SE} ; \mathrm{BA}$ \\
\hline S4 & $\mathrm{C} ; \mathrm{PE}$ & $\mathrm{C}$ & SE \\
\hline S5 & $\mathrm{N} ; \mathrm{PE}$ & $\mathrm{C} ; \mathrm{PE} ; \mathrm{N}$ & $\mathrm{SE}$ \\
\hline S6 & $\mathrm{C} ; \mathrm{N}$ & $\mathrm{C}$ & $\mathrm{N} ; \mathrm{SE}$ \\
\hline S7 & $\mathrm{C} ; \mathrm{N}$ & $\mathrm{N}$ & $\mathrm{C} ; \mathrm{N} ; \mathrm{SE} ; \mathrm{BA}$ \\
\hline S8 & Off topic & $\mathrm{C}$ & $\mathrm{SE}$ \\
\hline S9 & $\mathrm{C} ; \mathrm{PE}$ & $\mathrm{C}$ & PE; SE \\
\hline S10 & $\mathrm{PE}$ & Missing & Missing \\
\hline S11 & $\mathrm{C}$ & $\mathrm{C}$ & $\mathrm{SE}$ \\
\hline $\mathrm{S} 12$ & $\mathrm{C}$ & $\mathrm{C}$ & $\mathrm{C} ; \mathrm{N}$ \\
\hline S13 & $\mathrm{C}$ & $\mathrm{C}$ & $\mathrm{SE}$ \\
\hline $\mathrm{S} 14$ & $\mathrm{SE}$ & $\mathrm{C} ; \mathrm{N}$ & $\mathrm{SE} ; \mathrm{N}$ \\
\hline $\mathrm{S} 15$ & $\mathrm{C} ; \mathrm{PE} ; \mathrm{SE}$ & $\mathrm{C}$ & $\mathrm{SE}$ \\
\hline S16 & $\mathrm{C}$ & $\mathrm{C}$ & $\mathrm{SE} ; \mathrm{N}$ \\
\hline S17 & $\mathrm{C}$ & $\mathrm{C}$ & $\mathrm{SE}$ \\
\hline S18 & $\mathrm{C}$; SE; BA & $\mathrm{C}$ & $\mathrm{C}$; SE; BA \\
\hline S19 & $\mathrm{N} ; \mathrm{PE}$ & $\mathrm{C}$ & $\mathrm{C} ; \mathrm{PE}$ \\
\hline S20 & $\mathrm{C}$ & $\mathrm{C}$ & $\mathrm{SE}$ \\
\hline $\mathrm{S} 21$ & $\mathrm{C} ; \mathrm{PE}$ & $\mathrm{C}$ & $\mathrm{SE}$ \\
\hline $\mathrm{S} 22$ & $\mathrm{C}$ & $C ; \mathrm{N}$ & $\mathrm{C} ; \mathrm{SE}$ \\
\hline $\mathrm{S} 23$ & $\mathrm{C} ; \mathrm{N}$ & $\mathrm{C} ; \mathrm{N}$ & SE \\
\hline $\mathrm{S} 24$ & $\mathrm{C} ; \mathrm{PE}$ & $\mathrm{C}$ & SE \\
\hline
\end{tabular}

Codes:

$\mathrm{C}=$ effortful use of strategies learned to assess credibility and factual accuracy, such as use of CRAAP test elements or trusted sites

$\mathrm{N}=$ Naïve or misleading credibility indicators, such as "has facts" or looks

professional;

$\mathrm{PE}=$ references to personal experience or relevance

$\mathrm{SE}=$ refers to social or emotional elements of the message

$\mathrm{BA}=$ active consideration of need to balance social/emotional elements with factual accuracy.

Off topic or Missing = participant talked around topic or interview was cut short.

Coding details available: Wineburg, McGrew, Breakstone, \& Ortega (2016). 
The categories of criteria used as participants engaged in each task are presented in Table 2. It is worth reiterating here that, given the small sample size, generalizations about what is typical behavior for youth are not warranted.

\section{Section One: Attention to Factual Accuracy Varied by Practice}

The first set of analyses focused on whether participants applied considerations for factual accuracy not just when being asked to do so as part of an evaluation task but also when searching for and circulating media. As described below and illustrated in Table 2, when asked to evaluate information presented to them, participants primarily conceptualized this task as one of assessing the factual accuracy of the information and engaged in effortful analysis of the credibility of the media presented to them using strategies they had previously learned. In searching for information, attention to factual accuracy was common but frequently used alongside and sometimes substituted by criteria such as personal experience or social and emotional elements of the media. In the task of circulation, factual accuracy was far less commonly mentioned as a consideration, and facts were sometimes mentioned as a distractor or negative component of the message. Social and emotional considerations were given priority.

Search: How do you find useful information? When asked to find information that would be useful for the purposes of convincing others that their issue is a problem worth paying attention to, participants frequently $(n=18)$ referred to the credibility of information as a criterion for deciding whether they would use it or move on and keep searching. For example, one participant noted that they would choose "probably the first thing that comes up," but then went on to say, "You've got to check the source on this because it's definitely - it's clearly a website with a purpose." However, during this task, it was also common to switch between factual and nonfactual considerations $(n=10)$.

For example, when asked where to find information about LGBTQ rights, a student suggested starting with Tumblr, "Because that's just the main - that's a more interactive platform. There's a lot of people who, like, talk about it [the issue being researched] on there and voice their opinions on it." After discussing the strategy of accumulating multiple voices through Tumblr, when asked whether they would use the same approach for finding out how many young people were impacted in the local area, the participant noted, "I'd probably Google it if I was looking for a straight statistic." In this case, the participant understood that Tumblr was not the best source for getting factually accurate information about statistics related the issue, but the first impulse was to view the question of "useful" information for raising awareness as not necessarily requiring statistics about the scope of the problem or impact on people.

Another consideration that emerged when participants were asked to find useful information for the task of issue advocacy was whether they had 
personal experience $(n=8)$ with the source. For example, when searching for information on teen pregnancy a participant noted, "Here's [local organization's website], teen pregnancy and parenting, focus on [local city]. Oh, here, the [neighboring city] pregnant teens, that's actually, like - I've been there, too, so it's pretty helpful."

Evalution: Is this a good source? The next phase of the task asked participants explicitly to evaluate whether the information they were being presented was trustworthy. In this case, most participants $(n=20)$ engaged in effortful analysis, using criteria they had learned previously. For example, multiple participants suggested looking for information about the source or the author in order to learn more about what kind of information they were drawing on and whether they had any biases, as in the case of this student, "So main thing... 'study shows that teens struggle to find work.' It says study, so that's the indicator. I should trust it. I may do some research on the editor, [name] for the [Local Newspaper]. Maybe read some of his other articles to see if it's like has a bias or doesn't have a bias." Participants were also conscious of checking to see if the source had motives of profit or self-promotion. For example, "Well, it seems pretty good. You just have to be careful like if you see something really biased or when you see the website trying to give themselves extra credits, like "oh, we can do this,".... Other common strategies were to focus on the recency of the information and relevance for the task of raising awareness about the issue within their city.

Very few $(n=3)$ gave answers that relied solely on naïve or misleading indicators of credibility, such as site layout, the presence of facts or assuming that a org designation confers legitimacy. Within this group, one participant included considerations of personal experience in their judgment of credibility by suggesting that the best way to assess whether the source was accurate would be to interview someone with direct experience.

Circulation: Which one would you share? When participants were asked to choose among 3 media sources (video, blog and infographic) to circulate to others for the purposes of raising awareness, the factual accuracy of the information was infrequently raised as a concern (5 participants mentioned it). Rather, taking the perspective of trying to catch the attention of and persuade an audience, participants prioritized social and emotional elements such as: visual appeal, simplicity of message, or emotional appeal without raising concerns about factual accuracy $(\mathrm{n}=17)$.

Within this group, one reason for prioritizing social and emotional elements was based on the view that their potential audiences would not be interested in facts and that the best messages would be those that were simple and require the least cognitive processing. For example one participant chose a user generated video with no factual evidence, explaining:

...because it's better at capturing people's attention. Whereas, like, especially if you're working with high schoolers, to show them - a lot 
of kids don't really want to read it. Or the statistical information will go in through one ear and out the other. So, I think the video's better just because it's more interactive, I guess.

A less common approach $(n=1)$ was to decide what to circulate based entirely on the credibility of the media, as in the case of this participant who, when presented with the 3 options to circulate noted, "A blog's biased," and chose the infographic because, "you can't argue with facts." While this participant did not follow up to look for evidence that the source of the facts was credible, their decision-making was informed by consideration of bias and factual evidence.

\section{Section Two:}

\section{Multiple Indicators and Online Context Add to Task Complexity}

Another set of barriers to participants' attention to factual accuracy lay in challenges in effectively using credibility strategies in contexts that are typical for online civic media. This included figuring out what to do when there are missing or contradictory indicators of credibility, understanding the credibility of mission-based sources (e.g. nonprofit advocacy groups), making sense of articles that are embedded in websites or platforms that contain other media, and interpreting information presented via organizational blog.

Missing or conflicting indicators of credibility. As mentioned in section one, a majority of the participants in this study had received some training on assessing the credibility of online sources and used some of those strategies when asked explicitly to evaluate an online source. The ability to use multiple criteria to assess information and triangulate to come up with an accurate view of an issue is a critical component of civic online reasoning (McGrew et al., 2018). These skills allow people to make use of a media environment that includes institutional sources that they seek out but also media that is shared by friends, family and acquaintances or created by those who may not have access to those institutions.

In spite of knowing the strategies and seeking to use them, participants struggled to use multiple strategies simultaneously to arrive at the best answer. For example, one participant when asked to evaluate a source began by describing the process similar to that represented in the widely used CRAAP test of media quality, "First you have to look at the title and when was it published, who published it, what they said about it, and then what information exactly, what numbers, what percentages [to decide if it's] trustworthy." As the participant continued, they noted that the information was relevant to the topic of teen pregnancy, "by looking at the age and the numbers, that gives me one way I can trust it," but that, "then when it comes to, like, the author and the day and some other information, I don't see that. So that's one way I can't trust it." Faced with competing indicators, the participant concluded, "But then when I really come to, like, if it's trustworthy or not and see all the numbers and all 
the information they said about it, then that makes me trust it more." Faced with competing multiple indicators, the participant knew what to look for, but ultimately fell back on a gut feeling related to the appearance and presence of facts.

Mission-based sources. Another source of confusion that emerged was how to interpret the credibility of media sourced through mission-based organizations. Advocacy groups may curate or conduct their own empirical research with attention to standards of evidence but also have a specific mission and engage in fundraising. As demonstrated below, this can create challenges for youth who are trying to judge whether and how to use information they encounter online for the purposes of issue advocacy. One student explained:

So it says "Join the children's movement of California." So this is probably like a group based thing so then you question the reliability of it because it's not really a true author. ... If somebody asks you where did you find it from and you say a group, children's movement they probably wouldn't [trails off].

When it comes to research and information about issues of public concern, mission-based organizations play an important role in curating relevant information and filling in gaps that may be left by trends in academic publication and government funded research. Additionally, because they are not behind a paywall and can release information quickly, these sources are likely to be frequently encountered in the context of everyday civic media use. At the same time, such sources may not have the same standards of evidence or rules about presentation of information that apply to sources such as newspapers, government regulated research organizations or academic publishing.

Embedded and/or decontextualized media. When accessing information online, articles that may be rigorously sourced are often embedded in contexts (social media sites, blogs, online newspapers, websites) that also include irrelevant or misleading information as well. Thus the ability to focus attention on the most relevant indicators of credibility within such a context is an important element of the task of digital media literacy. For example, a student who was reviewing an article published in a local newspaper noted, "If it's all for - okay. Well, I'm kind of - yes. But I'm looking at these side ads and... not really." Following prompting by the interviewer to clarify, the participant noted, "Well, it is credible. It's credible, but that side ad just gives me a feeling that it's probably just a fake site." Here the participant demonstrated confidence in newspaper articles as credible but struggled with the competing indicators of advertising present next to the article.

Making sense of blogs. The final area of challenge that came up was the challenge of understanding whether and how to use information 
disseminated via blog. Whereas blogs are often thought of as personal diaries, this format has become popular as a dissemination tool for a range of organizations, particularly for those who are interested in curating and commenting on recent developments about social issues. The challenge is that this format can make them difficult to assess as resources.

For example, during the circulation task, one option for the issue of Youth Unemployment was to share a blog produced by a mission-based organization aligned with a major university that brings together research, youth voices and advocacy. The blog included a blend of factual evidence and personal narrative. In this context, the participant struggled a bit with the competing indicators of "blog," personal experience, and presence of facts. For example, the participant said, "Well in a blog you could lie. Like people pretty much just post what they think. Yeah so it's not really accurate but it also talks about people's personal experience so there's kind of like a between..." The participant then went on to conclude “...it is a good - pretty much a good source to search up or present...," suggesting that they would use it but verify the information. Similarly, a during the search portion of the task, a participant came upon a blog hosted by a major university, and noted, "It's from a college, [Major University] School of Information," but then when asked whether there is useful information there, noted "It's kind of helpful, but then it's like, it's kind of personal point of views [sic]."

\section{Section Three: Coordinating Personal Experience, Accuracy \& Emotion}

Using media for issue advocacy often requires balancing multiple considerations. It can involve trying to gain an accurate understanding of the scope and impact of a problem. It can also involve trying to find ways to articulate one's own experiences as part of a public and collective issue. It can also involve trying to capture the hearts, imaginations and minds of others to see things from one's own viewpoint and to join in action. When thinking about these goals within the broader context of how they impact the overall quality of democracy, it becomes clear that there is a need to pay attention to how these goals are balanced. In this section, I draw on examples where participants raised concerns for factual accuracy as well as the social and emotional elements of the message to highlight differences in how these considerations are used and how participants may better integrate them.

Raise multiple considerations with no attempt at integration. While concerns for factual accuracy and personal experience were both raised during the search portion of the task, they tended to come up separately without much attempt to discuss which priority should take precedent or how to take both into account. For example, after first suggesting going to YouTube to find information about LGBTQ youth discrimination, because, as one student put it, "...there are a lot of good like YouTube videos that have people who have gone through that sort of thing, talking about their experience," the participant 
then chose a different source with statistics and discussed strategies for assessing whether that source was valid.

For participants who had personal experience with an issue, being teen parents themselves or struggling to find work to allow them to contribute to their families, these personal experiences came up during the search portion of the interview as well as a reason to affirm that the issue was important and deserving of attention. However, for those who did then focus on searches for information that would provide a broader view of the issue, there was no tendency to compare similarities or discrepancies between the two types of sources.

Choosing between competing priorities. Another approach was to view accuracy and persuasiveness as competing priorities. For example, during the search task, a participant first raised the idea of going to government sites to seek information, but then quickly noted that they should "look for something that like - emotional, sort of, that would like show it's a problem. ...... So not like the government. They try to be sort of neutral or like impartial." This participant noted, "I mean I usually use [government sites] for like straight up info," but then noted that for this they needed to, "Look for something that would strike some sort of downfall or suggest that it's a problem." Within this context, the participant demonstrated recognition of consideration of factual accuracy and persuasiveness as elements of the task of issue advocacy, but ultimately framed them as competing priorities.

Creating an integrated strategy using multiple sources. While not common, another strategy was to argue for using multiple sources, one with evidence and one with personal narrative, to inform their understanding or communications. For example, when one participant was asked to choose between media to circulate to raise awareness, the response raised both considerations for credibility and social and emotional elements and ultimately suggested using a different, combined approach that integrated the two:

The blog on the other hand that would be like something you would try to aim for because it's coming from the teens themselves so it makes more sense when a teen says I'm being violated this way and my safety is - safety matters because of this so finding that would be most important depending on - But it has to be a wide base. It can't just be one student because you want to give the opinion that it happens to more than one. And then the video, the second because then again we don't know how they got the facts in it because it didn't seem that credible on the basis of this was made by or created by but it did have statistics that may match them, those of the graph so if you was to combine them two then that would make way more sense. 


\section{DISCUSSION}

The broad research question addressed in this study focused on identifying barriers to youths' attention to factual accuracy in the context of everyday civic media literacy. It is important to note that the small size of this convenience sample and year of data collection (2014) preclude drawing conclusions about what is typical or which challenges are most prevalent. However, the findings presented here align with some recent theoretical developments in the conceptualization of civic media literacy. This study allows us to ground some recent ideas raised in the literature in practical examples of how they play out as youth encounter media, and how educators might respond and provide some direction for future research and practice.

While there is widespread agreement that the spread of misinformation is a critical issue for democratic education, this study illustrates the complexity of the task of using information accurately and responsibly in the context everyday civic media use. In line with existing research (Martens \& Hobbs, 2015; Kahne \& Bowyer, 2017), participants in this study who had prior access to media literacy education used these strategies to assess evidence when the asked to assess the credibility of information. However, as McGrew et al., (2018) recently also found, they struggled to use these criteria when faced with multiple or conflicting indicators of credibility. Additionally, the study points to two new avenues for understanding and supporting civic media literacy.

\section{Balancing Relevance, Persuasion and Factual Accuracy}

One dynamic that emerged in this study was that, when searching for information for the purposes of issue advocacy, participants sometimes wavered between interest in factual accuracy vs. interest in personal relevance or social and emotional considerations. One response may be to urge youth away from media that includes personal narrative or emotional appeal. However, the way in which youth think about civic engagement and the nature of the media they are likely to encounter both suggest against this approach.

First, it ignores the multiple findings that the sources that best align with standards of objectivity are often unappealing to youth who feel that the information presented is either irrelevant or misrepresentative of them and their concerns (Clark \& Marchi, 2017; Common Sense Media, 2017). It also ignores the fact that civic issues are inherently social and emotional. Any matter worthy of public debate and effort has real world consequences and the potential to harm or help, promote justice or injustice which should evoke some sense of emotion. Stripping media of these elements, as Grabe \& Myrick (2016) have argued, may simply discourage engagement and runs counter to the goals of democracy. Mihailidis' (2009) finding that civic education that focuses on skill attainment alone is associated with lower rates of interest in dialogue and participation reinforces this argument. 
Another conclusion is that civic media literacy requires the ability to integrate and balance the importance of the personal, individual experience and moral consequences of civic information with the available (and unavailable) evidence. The accompanying implication is that civic media literacy education requires taking all of these elements seriously and helping youth to integrate these elements. Such an approach is aligned with Mihailidis \& Viotty's (2017) arguments for a more situated version of media literacy which focuses on media literacy as including an emphasis on "spreadable connectivity," "mechanisms for caring," "everyday engagement" "and "intentionally civic."

Furthermore, given the growing observation that youth exposure to civic and political stories is through social media, the likelihood that such news will be embedded in a social and emotional context is high. Media now comes with comments, from friends and family, with pictures or jokes, blended with news about entertainment and non-political topics. Teaching youth to construct a coherent understanding of news that takes into account the social and emotional stakes is likely to be better aligned to the current realities of civic media use.

\section{The Circulation and the Ethics of Sharing in Civic Media Literacy}

Within media literacy education, efforts to teach for savvy consumption of information are well represented, as are efforts to teach youth to express their voices through dialogue, circulation and production (Crampton, Scharber, Lewis \& Majors, 2018; Hobbs, 2010; Kahne et al., 2016; Middaugh \& Evans, 2018). These elements are also discussed side-by-side as components of an overarching set of practices that make up media literacy. However, concerns about misinformation are usually confined to analysis of youth involved in the explicit task of assessing credibility (Kahne \& Bowyer, 2017; Martens \& Hobbs, 2015) and sometimes in relation to production of media (Crampton et al., 2018; Hobbs, 2010; Garcia, Mirra, Morrell, Martinez, \& Scorza, 2015), but not systematically discussed in relation to the circulation of media.

In light of the finding that youth frequently ignored or rejected concerns about factual accuracy in their decisions to circulate media, there is reason to believe that there is a gap in current approaches to teaching civic media literacy. All participants in this study understood that not all media can be trusted and the need to protect themselves against misinformation by asking questions about the sources they encounter. However, when asked about the use of information to raise awareness or get others to care, concern for the credibility of the media being shared was subsumed by concerns for emotional impact or ease of ingestion.

In the era of participatory media and participatory politics, where the citizenry as a network of individuals plays a strong role in the circulation and shaping of public information, there is perhaps a need to discuss the ethics of sharing in everyday practice. On one hand, a person may responsibly share an opinion without citing evidence to either reflect their individual experience or 
interpretation of events. On the other hand, statements with strong assertions often imply that there is some factual evidence behind them and that the author is willing to vouch for the veracity of the statement, as indicated by Kahne and Bowyer's (2017) finding that youth tended to endorse emotive media without facts embedded as accurate. Thus, sharing media with others takes on an ethical component as it has the potential to spread misunderstandings for misinformation.

Discussions with youth are needed to examine their role in the media environment, both in ensuring their rights of access to information and expression but also their responsibilities as media circulators who are providing information to others. Telling youth not to share their opinions or humorous media runs the risk of taking away the passion, emotion and humor, and turning political activity into an academic exercise. However, engaging youth in the habit of reflecting on what they share before they share it, "Is this something you're willing to vouch for? Why?" may achieve a similar goal. Making this a routine part of civic media literacy education can help youth to individually consider and act with civic intention but may also contribute to a larger set of shared norms that make up a collective set of ethics of sharing which are still evolving alongside our technology.

\section{Limitations and Implications for Research and Practice}

In addition to including a small convenience sample of youth, one of the primary limitations of this study is that it was conducted in 2014 , prior to the 2016 election which dramatically heightened awareness of the role of social media in spreading fake news. It is possible that youth are now more likely to think before they share. However, in light of aspects of adolescent cognitive development that can make it challenging for youth to balance social and emotional influences while engaged in logical reasoning, it is likely that many will need support and practice in balancing these elements when making quick judgments about circulation of information (Middaugh, in press). Finally, while the Issue Advocacy Task was designed to replicate some of the dynamics of civic media literacy in practice, these tasks are not the same as how youth may navigate civic media in a purely naturalistic setting.

\section{REFERENCES}

Barber, B. (1984). Strong democracy: Participatory politics for a new age. Berkeley: University of California Press.

Berry, J. \& Sobieraj, S. (2014). The outrage industry: Political opinion media and the new incivility. New York, NY: Oxford University Press.

Blevins, B., LeCompte, K. \& Wells, S. (2016). Innovations in civic education: Developing civic agency through action civics. Theory and Research in Social Education, 44(3), 344-84. 
Braun, V. and Clarke, V. (2006) Using thematic analysis in psychology. Qualitative Research in Psychology, 3 (2). pp. 77-101.

Clark, L. S. \& Marchi, R. (2017). Young people and the future of news: Social media and the rise of connective journalism. New York, NY:

Cambridge University Press.

Cohen, C. J. \& Kahne, J. (2012). Participatory politics: New media and youth political action. A DML Working Paper.

Common Sense Media. (2017). News and America's kids: How young people perceive and are impacted by the news. Retrieved from https://www.commonsensemedia.org/sites/default/files/uploads/researc h/2017_commonsense_newsandamericaskids.pdf

Crampton, A., Scharber, C., Lewis, C. \& Majors, Y. (2018). Meaningful and expansive: Literacy learning through technology-mediated productions. Journal of Adolescent \& Adult Literacy, 61(5), 573-6.

Dewey, J. (1916). Democracy and education. New York: The Free Press.

Dewey, J. (1927/1954). The public and its problems. Athens, OH: Swallow Press.

Garcia, A., Mirra, N., Morrell, E., Martinez, A. \& Scorza, D. (2015). The council of youth research: Critical literacy and civic agency in the digital age. Reading \& Writing Quarterly, 31(2), 155-67. doi: 10.1080/10573569.2014.962203

Grabe, M. and Myrick, J. (2016). Informed citizenship in a media-centric way of life. Journal of Communication, 66, 215-35.

Graf, J., Erba, J. \& Harn, R. (2017). The role of civility and anonymity on perceptions of online comments. Mass Communication and Society, 20:4, 526-49.

Hobbs, R. (2010). Digital and media literacy: Connecting culture and classroom. Thousand Oaks, CA: Corwin/Sage.

Hobbs, R., Donnelly, K., Friesem, J. \& Moen, M. (2013). Learning to engage: how positive attitudes about the news, media literacy, and video production contribute to adolescent civic engagement. Educational Media International, 50(4), 231-46.

Jenkins, H., Purushotma, R., Clinton, K., Weigel, M. \& Robinson, A. (2006). Confronting the challenges of participatory culture: Media education for the $21^{\text {st }}$ century. Chicago: The John D. and Catherine T. MacArthur Foundation.

Kahne, J. \& Bowyer, B. (2017). Educating for democracy in a partisan age: Confronting the challenges of motivated reasoning and misinformation. American Education Research Journal, 54(1), 3-34.

Kahne, J., Hodgin, E. \& Eidman-Aahdahl, E. (2016). Redesigning Civic Education for the Digital Age: Participatory Politics and the Pursuit of Democratic Engagement. Theory \& Research in Social Education, 44(1), 1-35. 
Lan, C. (2013). Democratic education in the new media era: Toward a framework of democratic media literacy. Ohio Social Studies Review, 50(1), 51-62.

Martens, H., \& Hobbs, R. (2015). How media literacy supports civic engagement in a digital age. Atlantic Journal of Communication, 23, 120-137.

McGrew, S., Breakstone, J., Ortega, T., Smith, M., \& Wineburg, S. (2018). Can students evaluate online sources? Learning from assessments of civic online reasoning. Theory \& Research in Social Education. Advance online publication.

Middaugh, E. (in press). Teens, Social Media \& Fake News. Middaugh, E. (In Press). Teens, social media and fake news. Chapter 3. In W. Journell (Ed). Fake news: What it is, why it is problematic, and what educators can do about it. New York: Teachers College Press. Approved by Review Board June, 2018.

Middaugh, E. \& Evans, C. (2018). Middaugh, E. \& Evans, C. (2018). Did you know?!...Supporting online public voice in youth. Theory and Research in Social Education, 1 - 29.

Mihailidis, P. (2018). Civic media literacies: Re-Imagining engagement for civic intentionality. Learning, Media and Technology, 43:2, 153-64.

Mihailidis, P. (2009). The new civic education: Media literacy and youth empowerment worldwide (Report). Washington, DC: Center for International Media Assistance at the National Endowment for Democracy. Retrieved from http://cima.ned.org/publications/ researchreports/media-literacy-empowering-youth-worldwide

Mihailidis, P. \& Viotty, S. (2017). Spreadable spectacle in digital culture: Civic expression, fake news, and the role of media literacies in "postfact" society. American Behavioral Scientist, 61(4).

Tandoc, E., Lim, Z. \& Ling, R. (2018). Defining "Fake News", Digital Journalism, 6:2, 137-153, DOI: 10.1080/21670811.2017.1360143

Wineburg, S. McGrew, S., Breakstone, J., Ortega, T (2016). Evaluating Information: The Cornerstone of Civic Online Reasoning. Stanford Digital Repository. Available at: http://purl.stanford.edu/fv751yt5934

\section{Acknowledgements}

This research was made possible by the generous support of the S.D. Bechtel Jr. Foundation and the John D. \& Catherine T. MacArthur Foundation through the Educator Innovator Fund. While the author bears sole responsibility for the content of this paper, I would like to thank thank Young Whan Choi, Elyse Eidman-Aahdahl, Chris Evans, Erica Hodgin, Joseph Kahne, Ravi Lau, Paul Oh, Stan Pesick \& Shelly Weintraub as well as the teachers and students who gave their time. 